\title{
Female employment and occupational changes in the 1990s: How is the EU performing relative to the US?
}

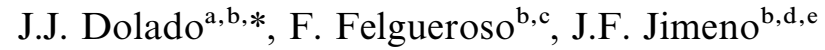 \\ ${ }^{a}$ Department of Economics, University of Carlos III, c/Madrid, 126-Edificio Luis Vives, \\ 28903 Getafe, Madrid, Spain \\ ${ }^{\mathrm{b}}$ Centre for Economic Policy Research, London, UK \\ ${ }^{\mathrm{c}}$ Universidad de Oviedo, Oviedo, Spain \\ ${ }^{\mathrm{d}}$ Universidad de Alcalá, Alcalá de Henares, Spain \\ ${ }^{\mathrm{e}}$ FEDEA, Madrid, Spain
}

\begin{abstract}
This paper provides a comparison of the incidence and composition of female employment both in the EU and in the US. Despite a significant increase in female labour market participation in the EU, about $50 \%$ of the difference between the employment rates in the US and the EU can still be attributed to differences in the educational attainments and the employment rates of women aged 25-54. We highlight the main features of female employment in both areas, paying particular attention to the differences across age cohorts and educational levels. Our main findings are as follows: (i) the educational level of the EU female population is slowly converging to that of the US across age cohorts, (ii) the employment rates of less educated women are much lower in the EU than in the US (with the exceptions of the Scandinavian countries) even for women aged 25-34, and (iii) occupational segregation is lower for the younger highly educated women who seem to be entering more typically male occupations and less typically female occupations, although at a higher rate in the US than in the EU. (C) 2001 Elsevier Science B.V. All rights reserved.
\end{abstract}

JEL classification: $\mathrm{J} 16 ; \mathrm{J} 21 ; \mathrm{J} 44$

Keywords: Female employment; Occupational change; Occupational gender segregation

\footnotetext{
* Corresponding author. Dpto. de Economía, Universidad Carlos III, c/Madrid 126, 28903 Getafe, Madrid, Spain. Tel.: + 34-1-624-9300; fax: + 34-1-624-9313.

E-mail address: dolado@eco.uc3m.es (J.J. Dolado).
} 


\section{Introduction}

Over the last decade female participation rates have noticeably increased both in the EU (from 54.8\% to 59.5\%) and in the US (from $67.8 \%$ to $70.7 \%$ ), following a trend that dates back to the 1960s. Additionally, in the 1990s, total employment increased at an annual average rate of $0.4 \%$ in the EU and $1.5 \%$ in the US, while female employment increased at annual average rates of $0.9 \%$ and $1.9 \%$, respectively. Many explanations exist about the growing importance of women in the labour market. On the demand side, it has been pointed out that firms are more willing to hire women due to various factors such as the rise of service sectors and the decline of manual/production sectors, the development of new technologies which allow firms to substitute male for female workers, anti-discrimination policy measures, and the huge increase of higher education among women. ${ }^{1}$ On the supply side, it has been argued that lower fertility rates, the availability of new household technologies, and the emergence of flexibletime work have contributed to the increase in women's willingness to enter the labour market.

However, despite the existence of common patterns in women's participation in the labour market across both sides of the Atlantic, a large proportion of the employment rate differential between the US and the EU is still due to the lower female employment rate in the latter (which is about 14 percentage points lower). ${ }^{2}$ Thus, any detailed investigation of future trends in EU labour markets, relative to the US, should pay a great deal of attention to the increasing weight of female employment and the reasons accounting for its different performance across countries. A relevant dimension in this regard is the occupational composition of female employment, i.e. the nature of jobs held by women. Recently, occupational changes brought up by skill-biased technological progress and higher globalisation are changing the relative demand of skilled workers and, therefore, tend to affect the occupational composition of female employment (see, for instance, Black and Juhn, 2000, for the US). Those occupational changes seem to have accelerated the entry of women into the so-called 'non-traditional' female careers, with significant economic and social effects both on the distribution of resources within the family and on the functioning of the labour market (see, e.g. Costa, 2000).

\footnotetext{
${ }^{1}$ In most OECD countries, the proportion of women aged 25-29 years holding a university degree has nowadays overcome that for men within the same age cohort.

${ }^{2}$ This differential can be further broken down into about $10 \%$ points due to lower participation and $4 \%$ points due to higher unemployment. In 1999, the employment rate of women of 15-64 years of age was $53.1 \%$ in the EU, $67.6 \%$ in the US; participation rates were $59.5 \%$ and $70.7 \%$, respectively, while unemployment rates were $10.9 \%$ and $4.4 \%$, respectively.
} 
This paper provides a comparison of female employment patterns between the EU and the US that may be useful to guide further research on the sources of their different employment performances, as well as on the design of employment policies targeted at increasing EU employment. Using data from the 1999 European Labour Force Survey, for EU countries, and from the 1999 Current Population Survey, for the US, we highlight the main features of female employment in both areas. Women's employment status is affected by educational attainments and, in many EU countries, both employment status and educational attainments are heavily dependent upon age. Hence, our analysis of female employment pays particular attention to the labour market performance of the youngest female generations relative to other older cohorts, conditioning in all cases on their educational attainments. Unfortunately, homogenous data on workers' employment status, classified by educational attainment, for the Member States of the EU is only available since 1992 or 1995, in the case of Austria, Finland and Sweden. The lack of a longer time series dictates the choice of a single year, i.e. 1999, as the basis of the comparison, hoping to uncover convergence trends by examining whether the EU-US differentials in several dimensions of the female labour market, decline across age cohorts. Thus, the implicit assumption that we are making to disentangle trends from cohort effects, in the absence of data over time, is that the latter are common in both areas and, thus, that they vanish when taking differences between the US and the EU (see footnote 8).

The rest of the paper is structured as follows. We start in Section 2 by quantifying the relevance of female employment at explaining the current employment rate differential between the US and EU. In Section 3, we examine the occupational structure of female employment and its adjustment to those occupational changes that have taken place over the last decade. Section 4 analyses occupational gender segregation in the EU and in the US, conditioning on education and age. Lastly, Section 5 concludes with some final remarks and a few policy implications that can be drawn from our analysis.

\section{Employment rate differentials by age, gender and education}

The employment rate differential between the US and the EU in 1999 can be broken down in the following way:

$$
\begin{aligned}
e^{\mathrm{US}}-e^{\mathrm{EU}} & =\sum_{i} \alpha_{i}^{\mathrm{US}} e_{i}^{\mathrm{US}}-\sum_{i} \alpha_{i}^{\mathrm{EU}} e_{i}^{\mathrm{EU}} \\
& =\sum_{i} e_{i}^{\mathrm{EU}}\left(\alpha_{i}^{\mathrm{US}}-\alpha_{i}^{\mathrm{EU}}\right)+\sum_{i} \alpha_{i}^{\mathrm{US}}\left(e_{i}^{\mathrm{US}}-e_{i}^{\mathrm{EU}}\right)
\end{aligned}
$$

being $e^{\mathrm{EU}}$ and $e^{\mathrm{US}}$ the aggregate employment rates in the EU and the US, respectively, and $e_{i}$ and $\alpha_{i}$ the employment rate and the weight in total population 
of group $i$, defined over gender, three age cohorts (15-24, 25-54, and 55-64), and two educational attainments (tertiary education - i.e., university - and less than tertiary education). This decomposition yields two sources of the employment rate differential between the US and the EU: (i) a population composition effect, due to differences in population weights between both areas, holding employment rates equal at the EU levels, and (ii) an employment incidence effect, due to differences in employment rates, holding population weights at the US levels. The first two panels of Table 1 provide direct comparisons of the population shares and the employment rates across groups, while the last two panels list the proportion of the overall differential which is attributed to each group. ${ }^{3}$ The main finding is that $70 \%$ of the aggregate employment rate differential arises from the population composition and the employment incidence effect of women. A closer look at the individual contributions of the different groups indicates that the two main sources of the employment spread are: (i) the lower proportion of women 25-54 years of age with tertiary education in the EU relative to the US (6.5\% vs. 9.6\%, respectively) that accounts for $22 \%$ of the total spread, and (ii) the lower employment rate of women 25-54 years of age with less than tertiary education in the EU relative to the US (60\% vs. $71 \%$ ), which explains $24.1 \%$ of the spread. ${ }^{4}$ In other words, if the EU were to have both the same population weight of highly educated women aged 25-54 years old as the US, and an identical employment rate of less educated women in the same age bracket, then the current difference of $11 \%$ points between the US and the EU aggregate employment rates would be halved. ${ }^{5}$

The fact that the population weight of women aged 25-54 with a tertiary level of education is $3.1 \%$ points higher in the US than in the EU is due to both demographic factors and differences in the educational attainment of the older cohorts in such a broad age group. The proportion of women aged 25-54 in the working age population (16-64 years of age) is about $2.2 \%$ points higher in the US (1.8\% points for women aged $35-44$ years, and $0.4 \%$ points for women aged

\footnotetext{
${ }^{3}$ The EU figures exclude Ireland since data on the educational attainment of the female population were not made available by EUROSTAT.

${ }^{4}$ These results do not depend qualitatively on the choice of the benchmark employment rates or population weights. Had we chosen an alternative decomposition with the employment rates of the US and the population weights of the EU as benchmarks, then the population composition effect of women aged 25-54 with a university degree and the employment rate effect of women of the same age with less than tertiary education would have accounted for $22.1 \%$ and $24.9 \%$ of the difference of the employment rate between the EU and the US.

${ }^{5}$ The lower employment rates of youths and older workers (55-64) with less than tertiary education explains roughly the other half of the employment rate differential.
} 


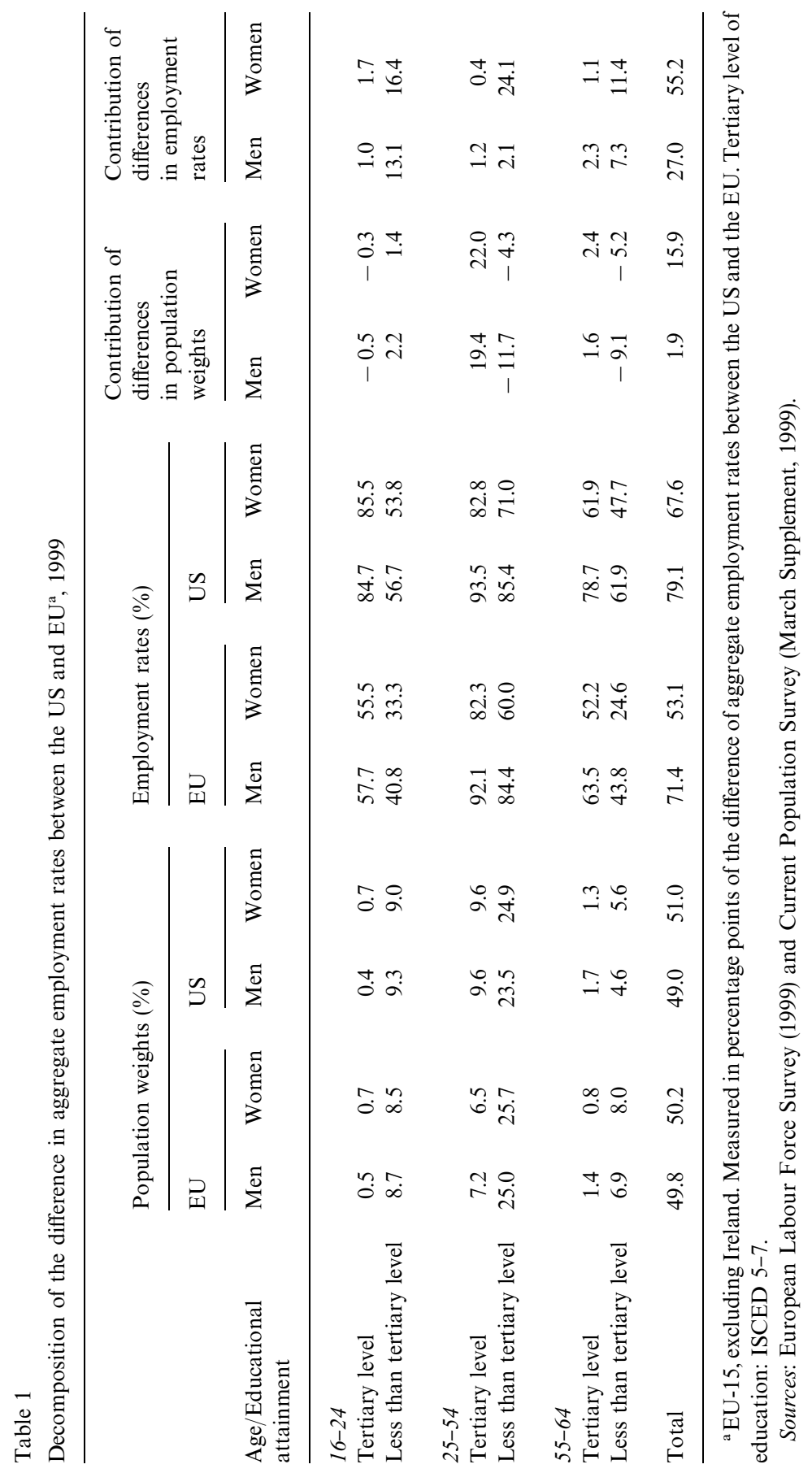


45-54). ${ }^{6}$ Differences in educational attainments are highest in the $45-54$ age group (the proportion of women with a tertiary education is $5.7 \%, 6.3 \%$, and $11.0 \%$ points lower in the EU for cohorts 25-34, 35-44, and 45-54, respectively). As depicted in Fig. 1, in most EU countries (with the only exceptions of Denmark, Germany, Italy, and Austria) the proportion of women with a tertiary level of education in the youngest cohort (25-34) is significantly larger than that of older cohorts (35-44 and 45-54), while in the US that proportion does not change so much across age groups. Thus, the decreasing pattern of educational attainment differentials along the different age cohorts indicates that the EU is converging towards the US in this dimension. There is, however, some considerable variation within the EU area. At one extreme there are the Scandinavian countries, with educational qualifications higher than the US for almost all age cohorts. At the other end there are countries like Austria, Germany, Italy and Portugal, which have a much lower proportion of women with a tertiary educational level, even for the youngest cohort. In the case of the first two countries, this can be accounted by the prevalence of the dual vocational system of education at the transition from school to work. Finally, in the remaining countries, women have overall lower educational attainments than in the US, although for the youngest cohort the differential is smaller and, in some cases, even negative. ${ }^{7}$

As regards the lower employment rates of women aged 25-54 years old with less than a tertiary level of education, the overall pattern is similar to that obtained earlier for the difference between population weights, i.e. a smaller differential for the youngest cohort and a wide dispersion across EU countries. On the one hand, the Nordic countries (with the unique exception of Finnish women aged 25-34) enjoy higher employment rates than those of the US. On the other hand, there are the Southern European countries that have employment rates about 20 (for the youngest cohort) and 30 percentage points (for the older cohorts) lower than the corresponding ones for the US. Thus, the joint picture is, broadly speaking, one of decreasing differentials between the US and EU as regards both the population weight of highly educated women and the employment rate of the less educated ones. In sum, despite the existence of noticeable variation among the EU countries and that significant overall differences still remain, it can be concluded that the younger female generations in the EU are

\footnotetext{
${ }^{6}$ The proportion of women aged $35-44$ in total population is $1.8 \%$ points higher in the US than in the EU. This is, in part, a reflection of the fact that the peak of the baby boom took place about a decade earlier in the US than in the EU. An additional reason is that the working age population excludes the prison population, which is significantly higher in the US.

${ }^{7}$ Goldin (1999) and Goldin and Katz $(1997,1999)$ have documented the increase of the educational attainments of the US population during the 20th century. This educational upgrading of the labour force has also taken place in the EU, although in some countries took place much later than in the US. For instance, in 1940 roughly $50 \%$ of the US youths already had a medium level of education-High School diploma, whereas the corresponding proportion for some EU countries was around 20\% (see Costa, 2000).
} 
$=25-34 \square 35-44 \mathbb{Z} 45-54$

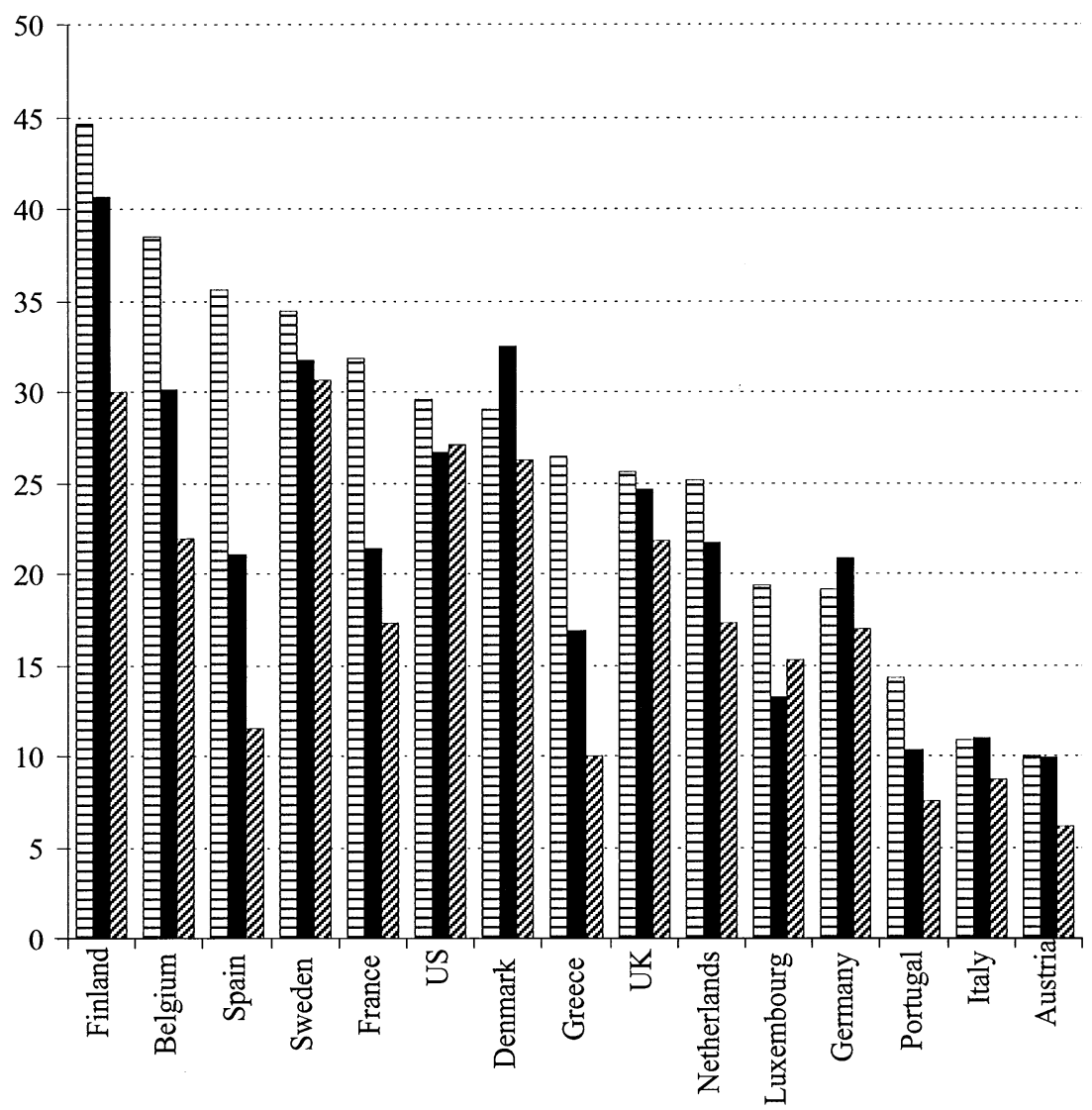

Source: EUROSTAT and CPS (March supplement).

Fig. 1. Proportion (\%) of women aged 25-54 with tertiary education in the EU and in the US, 1999.

getting closer to their US counterparts both in terms of education and employability, although they seem to be converging much faster in the former dimension than in the latter. ${ }^{8}$

${ }^{8}$ Differences in employment rates across age cohorts within a given country can be due to either cohort effects or to a time trend. However, insofar as the cohort effect is similar in the EU and in the US, a reduction of the employment rate differential across age cohorts can be interpreted as a sign of convergence. Arguably, the cohort effect varies across countries but it is unlikely that it could entirely explain this reduction. Since data disaggregated by educational attainment are not available for all EU countries before 1992, we cannot disentangle the cohort effect and the time trend for each area separately. 


\section{The occupational composition of female employment}

In order to analyse the evolution of the occupational structure of female employment in both areas, we consider nine broad occupational groups: professionals, non-manual low-skill occupations, and manual occupations in manufacturing and utilities, private services and social services, respectively. Table $2 \mathrm{a}$ reports the proportion of women of a given age and educational attainment level employed in each of these occupational groups in the US, while Table $2 b$ presents the differences between the US and the EU in this regard. The main differences in the occupational structure of employment between the US and the EU lie in: (i) the smaller weight of female employment in private services in the EU (being these differentials larger for women with lower levels of education and for professional jobs), (ii) the larger employability of less educated women into non-manual low skill jobs in social services in the US, and (iii) the larger proportion of women with high levels of education employed in social services in the EU, especially for the cohort aged 35-54, which just reflects the larger size of the public sector in this area.

As for women with tertiary levels of education, the youngest generation seems to be getting jobs in the private service sector, relative to the older generations, at a higher rate in the EU than in the US, as indicated by the smaller differential between both areas for the youngest cohort. This is not the case, however, for women with less than tertiary education in both private and social service sectors, where differentials are roughly constant are across age cohorts. By contrast, the rate at which young highly educated women are holding jobs in the social service sector is almost identical in both areas, having converged to about $38 \%$. Also, in the case of professional jobs in the private service sector, the proportion of women with tertiary education working in these jobs is almost $6 \%$ points higher in the US. It is noteworthy that this difference does not decline with age, and that the proportion of women in the youngest cohort, with tertiary education, working in non-manual low-skilled jobs in the EU is $2.6 \%$ points larger than in the US, which suggests that the 'under-utilisation' of women holding university degrees is higher in the EU. With regard to the employment of highly educated women in professional jobs in private services, the EU countries which look closer to the US are Austria, the Netherlands and the UK, albeit only for the youngest cohort, whilst the Southern Mediterranean countries are those who fare worst in this dimension. The remaining countries show both sizeable differences with the US and no significant patterns of a reduction across age cohorts. In contrast to private services, highly educated women in the EU have traditionally had larger employment opportunities in professional jobs in social services, particularly in the case of some Nordic countries, Austria, the Netherlands and Portugal. Nonetheless, the differences at the EU level for the youngest cohort have almost vanished and there are even four countries (Finland, France, Italy and Spain) with a lower proportion of highly educated young women employed in that sector than in the US. 
As for non-manual low skill jobs in private and social services, the proportion of women with low levels of education working in these jobs is about $3 \%$ points higher in the US, also with little variation across age cohorts. This fact may just reflect the smaller availability of low productivity jobs both in private and social services in the EU due to the existence of wage floors implied by various labour market regulations. Only the UK, in both private and social services, France and some of the Scandinavian countries, in the case of the social services, and Austria, in the case of the private services, show a larger female employment share than the US. ${ }^{9}$ In this respect, it should be remarked that the distinction between private and social services in the EU is very much related to the distinction between private and public service sectors and, hence, differences in the pay determination system between both sectors could be at the root of the varying employment opportunities of less educated women. These differences are almost negligible in the US, while there is no clear pattern with regard to either public-private differentials or to wage dispersion across both sectors within EU countries, which may be the reason behind the variety of individual country experiences. ${ }^{10}$

\section{Education, age and occupational segregation}

Since the 1980s biased technological progress and globalisation have increased the demand of skilled labour both in the US and in the EU. To the extent that women experienced a more intense skill upgrading than men, this should have favoured female employment. Occupational changes have also tended to increase employment in 'typical' female occupations (e.g. services) and to reduce it in 'typical' male occupations (manual/production jobs). Moreover, the entry of women into 'careers' makes them more prone to succeed at 'typical' male occupations. Both changes in the occupational mix of employment and changes in the sex composition of each occupation have resulted into a reduction of occupational segregation by gender (i.e. the tendency for women to work in different occupation than men) during the 1980s. ${ }^{11}$

In order to check if this decline in occupational dissimilarity by gender has continued at a similar rate in the US and in the EU over the 1990s we compute the widespread-used Duncan and Duncan (1955) index of segregation $\left(S_{t}\right)$ for

\footnotetext{
${ }^{9}$ The data for each EU country are available from the authors upon request.

${ }^{10}$ On public pay determination systems in the EU (see Elliott et al., 1999).

${ }^{11}$ See, for instance, Blau et al. (1998) and Costa (2000) for the US during the 1970-1990 period, and Anker (1998) for EU countries during the 1980s.
} 


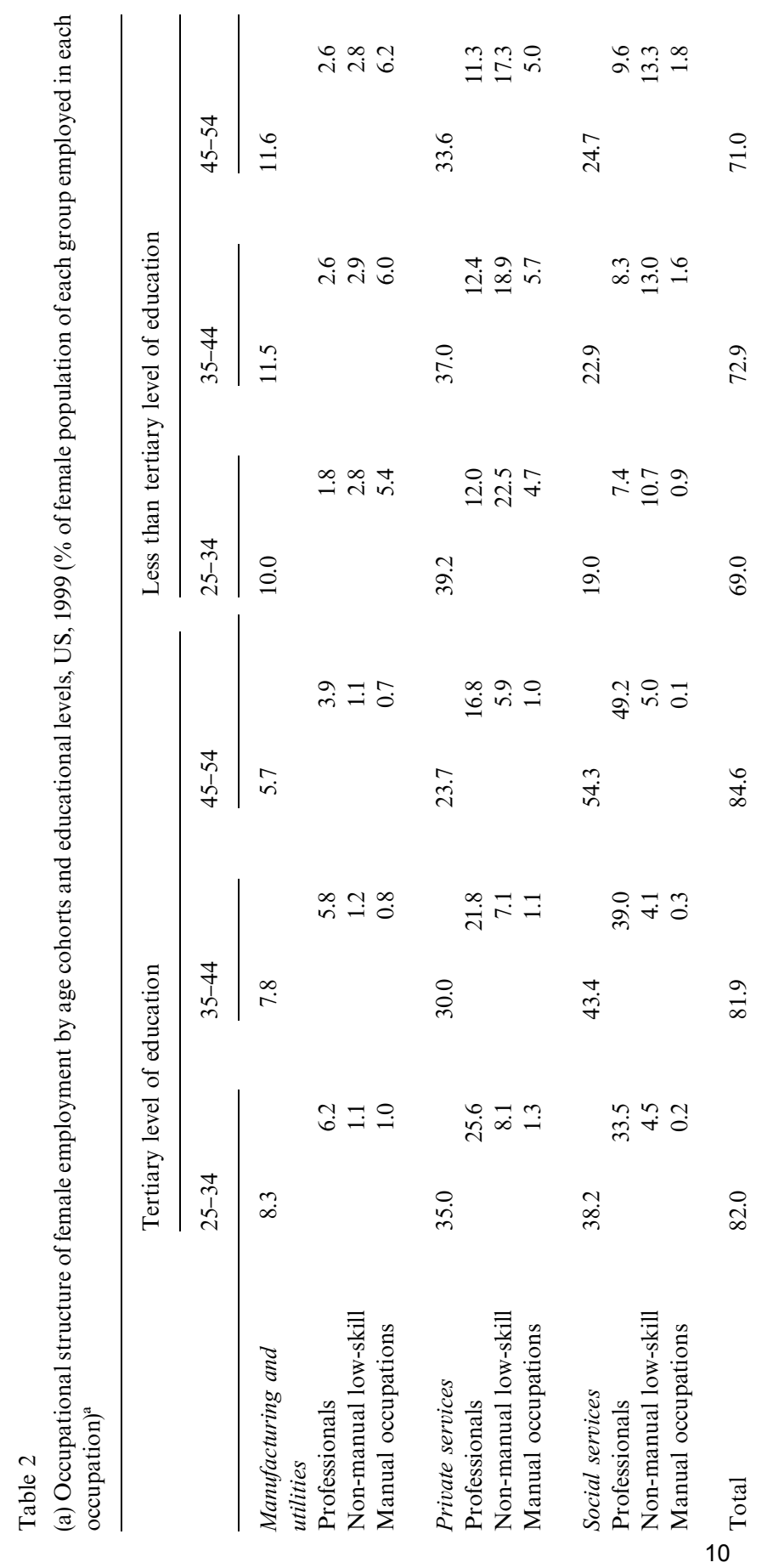




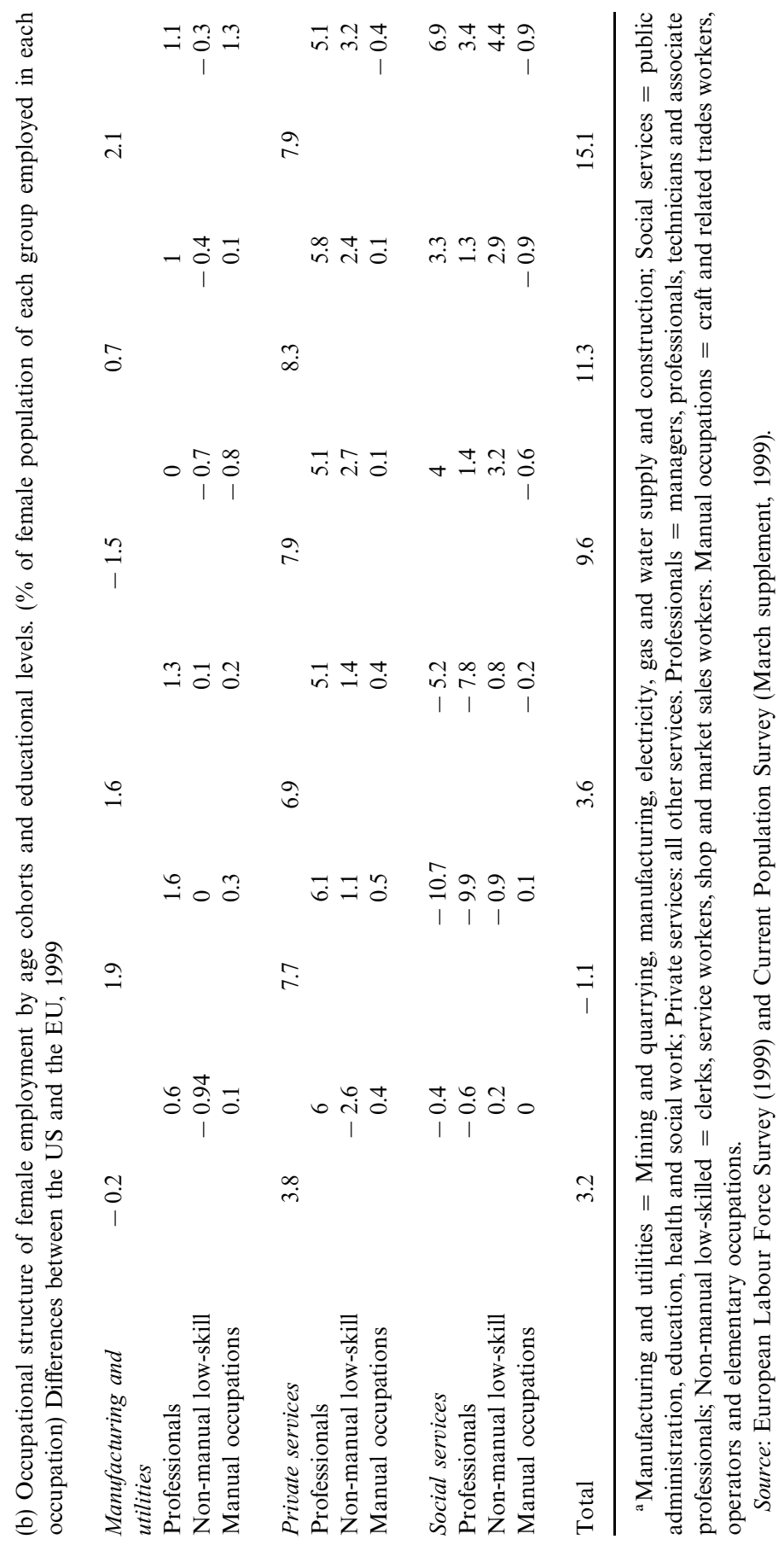


1999, distinguishing by age cohorts and educational attainments. This index is defined as follows:

$$
S_{t}=\frac{1}{2} \sum_{i}\left|m_{i t}-f_{i t}\right|
$$

where $m_{i t}\left(f_{i t}\right)$ is the proportion of the male (female) labour force employed in occupation $i$ at time $t$. This index, expressed as a percentage, can be loosely interpreted as the proportion of women (or men) who would have to change occupations for the occupational distribution of men and women to be the same. A value of $0 \%$ indicates that the distribution of women across occupations is the same as that of men, while a value of $100 \%$ indicates that women and men work in completely different occupations. To construct comparable indices across the US and the EU countries, we consider 108 occupations by combining nine occupational groups and 12 industrial sectors. ${ }^{12}$

Table 3 reports the occupational segregation by age cohorts in the US, and its difference with respect to the EU. In the US, occupational segregation is lowest for women with a tertiary level of education and declines across age cohorts for this group. Although it could be argued that this pattern could be due to age-specific occupational choices for highly educated women, there is strong evidence of a time trend towards lower segregation in the US (see Blau et al., 1998; Anker, 1998; Costa, 2000) and that this trend is related to their educational upgrading. As for the EU, occupational segregation is higher than in the US for highly educated women, particularly for women aged 35-44. Scandinavian countries and, to a lesser extent, Austria and Germany show the highest levels of occupational segregation for this group. The rest of the EU countries also suffer, in general, a higher degree of occupational segregation in the case of highly educated women. Moreover, there is no clear pattern of a reduction in the occupational segregation differential for the younger cohorts, which suggests that the trend towards less occupational segregation of highly educated women seems to be slower in the EU than in the US. ${ }^{13}$

It is also noteworthy that the occupational segregation of women with low levels of education is more similar across countries, with the only exception of Greece, Italy, and Portugal, which have the lowest levels of segregation

\footnotetext{
${ }^{12}$ The occupations considered are: (1) Executives, officials and managers, (2) Professionals, (3) Technicians and associate professionals, (4) Clerical personnel, (5) Sales and service workers, (6) Craft and related trade workers, (7) Manual workers, (8) Elementary occupations, (9) Agricultural workers. The industrial sectors are: (1) Agricultural, hunting and foresting, (2) Mining and quarrying, (3) Manufacturing, (4) Electricity and other utilities, (5) Construction, (6) Wholesale trade, and personal and social services, (7) Transportation, (8) Finance and Real State, (9) Public Administration, (10) Education, (11) Health and social work, and (12) Household and domestic services.

${ }^{13}$ The exceptions are Italy, Spain and the UK. However, the caveat in footnote 8 also applies here.
} 
Table 3

Segregation index, $1999(\%)$

\begin{tabular}{|c|c|c|c|c|c|c|}
\hline & \multicolumn{3}{|c|}{ Tertiary level of education } & \multicolumn{3}{|c|}{$\begin{array}{l}\text { Less than tertiary level of edu- } \\
\text { cation }\end{array}$} \\
\hline & $25-34$ & $35-44$ & $45-54$ & $25-34$ & $35-44$ & $45-54$ \\
\hline \multirow[t]{2}{*}{ US } & 31.4 & 36.0 & 42.3 & 49.6 & 49.1 & 50.9 \\
\hline & \multicolumn{6}{|c|}{ Differences between the US and the EU } \\
\hline EU & -3.8 & -4.9 & 0.4 & 2.7 & 0.5 & 2.7 \\
\hline Denmark & -13.1 & -20.4 & -11 & -0.5 & -8.2 & -7.1 \\
\hline Finland & -12.9 & -15.2 & -7.8 & -0.7 & -9.6 & -7.6 \\
\hline Sweden & -15 & -13 & -7.3 & 0.5 & -11 & -12.4 \\
\hline Austria & -7.5 & -8.1 & -4.8 & -3 & -3.4 & -1.2 \\
\hline Germany & -9.7 & -8.3 & -1 & -1.6 & -2.5 & 1.6 \\
\hline Belgium & -3.7 & 1.4 & -1 & -4.9 & -6.6 & -5.4 \\
\hline France & -4.3 & -3.1 & 2.8 & -2.5 & -3.4 & -0.7 \\
\hline Netherlands & -1.7 & -2.5 & 10 & 0.3 & -7.3 & -3.6 \\
\hline Greece & -1 & 2.8 & 10.5 & 6.1 & 6.3 & 6.2 \\
\hline Italy & 1.1 & 1.7 & -3.8 & 9.8 & 8.8 & 9.5 \\
\hline Portugal & -5 & -6.2 & -0.5 & 6.1 & 1.9 & 2.7 \\
\hline Spain & -5.6 & -7.1 & -7.2 & -0.6 & 1.9 & -0.8 \\
\hline UK & -3.9 & -11.6 & -8.8 & -0.3 & -7.6 & -6.9 \\
\hline
\end{tabular}

Source: European Labour Force Survey (1999) and Current Population Survey (March supplement, 1999).

in this regard. ${ }^{14}$ As for differences across age cohorts, the most noticeable finding is the smaller differential with respect to the US in the occupational segregation of younger women with low levels of education in Scandinavian countries. The reason why occupational segregation by gender has been highest in Nordic countries is mainly their unusually high weight of female employment in female-dominated occupations such as education, health care, and some social services (like child-care minders and other care-givers) which, in turn, help to support the high labour market participation of women in these countries (see Anker, 1998). By contrast, the low level of segregation of women with low levels of education in the Mediterranean countries (especially Greece, Portugal and Italy) can be interpreted in terms of the relative scarcity of occupations which are traditionally either male or female dominated, such as professionals in private and social services.

\footnotetext{
${ }^{14}$ This is in agreement with the evidence contained in Anker (1998) and Rubery and Fagan (1993), who use a much finer occupational classification.
} 


\section{Concluding remarks}

As much as half of the difference in the aggregate employment rates between the US and the EU can be attributed to the educational composition and the employment status of women aged 25-54. By analysing the differences in education and employment rates across different age cohorts and educational attainments for this group we have been able to document that:

(i) The population weights of highly educated women in the EU is slowly converging to those of the US by the ageing of the baby-boom generation in the US and the increase of educational attainments of the youngest generation of women (25-34) in most EU countries.

(ii) By contrast, the employment rates of less educated women are much lower in the EU than in the US (with the exceptions of the Scandinavian countries) even for women aged 25-34.

(iii) The occupational structure in both areas is dissimilar, with European women having a larger share of employment in social services, while North-American women have larger employment shares in private services. However, in both areas there is less occupational segregation for the younger highly educated women who seem to be entering more typically male occupations and less typically female occupations.

A declared primary policy goal in the EU is to achieve a larger employment rate in the next decade: At the Lisbon summit held in June 2000, EU governments pledged to reach an employment rate target of $70 \%$ by the year 2010 . Our previous findings indicate that the introduction/extension of policy measures favouring equal opportunities in the labour market (such as tax incentives for dual earner couples, child allowances, lower Social Security contributions for replacement of women under maternity leave, equal social rights of part-time workers, flexible work-time arrangements) should be key in achieving such a target. This has been recognised by policy-makers, to some extent, as shown by the fact that under the Luxembourg process, launched in November 1997, which co-ordinates employment policies across EU countries, equal opportunities in the labour market are one of the four pillars to which national employment policies should be targeted.

We have also documented that the youngest generation of highly educated women in the EU have employment rates and hold jobs that are increasingly similar to those of their US counterparts. Thus, the emphasis on improving the higher education of future generations should continue in order to achieve a further reduction of the employment rate differential between both areas. As for less educated women, the rise of their employment rates in the EU seemingly hinges upon a higher creation of jobs, in particular, in the service sector, for which it seems likely that some additional labour market deregulation is still needed. 


\section{Acknowledgements}

\section{We thank Olympia Bover and Etienne Wasmer for very valuable comments}

and advice.

\section{References}

Anker, R., 1998. Gender and Jobs. Sex Segregation and Occupations in the World. International Labour Office, Geneva.

Black, S.E., Juhn, C., 2000. The rise of female professionals: Are women responding to skill demand? American Economic Review, Papers and Proceedings 90 (2), 450-455.

Blau, F.D., Simpson, P., Anderson, D., 1998. Continuing Progress? Trends in Occupational Segregation in the United States over the 1970s and 1980s. NBER Working paper No. 6716.

Costa, D.L., 2000. From mill town to board room: The rise of women's Paid Labor. Journal of Economic Perspectives, Forthcoming.

Duncan, O.D., Duncan, B., 1955. A methodological analysis of segregation indexes. American Sociological Review 20, 210-217.

Elliott, R., Lucifora, C., Meurs, D., 1999. Public Sector Determination in the EU. MacMillan Press, Ltd, London.

Goldin, C., 1999. A brief history of education in the United States, NBER Working paper H0119.

Goldin, C., Katz, L.F., 1997. Why the United States led in education: lessons from secondary school expansion. NBER Working paper No. 6144.

Goldin, C., Katz, L.F., 1999. The shaping of higher education: the formative years in the United States, 1890 to 1940. Journal of Economic Perspectives 13 (1), 37-62.

Rubery, J., Fagan, C., 1993. Occupational segregation of women and men in the European Community. Social Europe (Suppl. 3). 